\title{
Dimensión social de la tecnología. Práctica tecnológica VINICULTURA ARTESANAL URBANA COMO ELEMENTO DE LA IDENTIDAD Cultural de Cienfuegos, Cuba (1994-2012)
}

\author{
SOCIAL DimENSION OF TECHNOLOGY. URBAN CRAFT WINEMAKING TECHNOLOGY \\ PRACTICE AS PART OF THE CULTURAL IDENTITY OF CIENFUEGOS, CUBA (1994-2012)
}

\author{
JUAN ANDRÉS SOSA PÉREZ \\ Universidad de Oviedo \\ jasosahg@gmail.com
}

RECIBIDO: $28 / 03 / 2016$

Resumen: El trabajo realiza un análisis de la Vinicultura Artesanal Urbana (VAU) en el contexto local de Cienfuegos, Cuba, desde el enfoque social de la ciencia y la tecnología, con el objetivo de fundamentar esa práctica tecnológica como un elemento de identidad cultural. Para ello se analizó en el período 1994-2012 la actividad de los asociados a los clubes de vinicultores Guanaroca y Jagua de esta ciudad. La novedad radica en que se fundamenta y se sistematiza teóricamente a la VAU como un elemento de identidad de la ciudad de Cienfuegos. Se realiza una aplicación novedosa en el orden metodológico de la propuesta teórica desarrollada por Bansart (1993) sobre la identidad cultural del yo colectivo, que permite destacarla como guía para caracterizar una práctica tecnológica como elemento de identidad de un contexto.

Palabras clave: Filosofía de la tecnología, identidad cultural, práctica tecnológica, vinicultura artesanal.

\begin{abstract}
The work carries out an analysis of the Urban Artisanal Winemaking (UAW) in the local context of Cienfuegos, Cuba, from the approach that generate the Social Studies of Science and Technology, in order to substantiate this technological practice as an element of cultural identity. For this, activity of the associates to winemakers' clubs Guanaroca and Jagua of that city was analyzed in the period $1994-2012$. The novelty is that it is theoretically based and systematized the UAW as an identity element of the city of Cienfuegos. It also carries out a novel application in the theoretical methodological proposal developed by Bansart (1993) on the cultural identity of the collective self, which allows highlight it as a guide to establish a technological practice as an element of identity context is performed.
\end{abstract}

Keywords: Philosophy of the technology, cultural identity, technological practice, artisan winemaking.

\section{Introducción}

El avance impetuoso de la ciencia y la tecnología que se inicia a mediados del 
siglo pasado y sus presiones sobre la sociedad, demandaron un enfoque emergente que permitiera comprender la esencia de lo humano en estas actividades y un acercamiento más viable de las mismas al público no experto. Surge y se desarrolla desde entonces, el enfoque social de la ciencia y la tecnología o, el cual llega al siglo XXI con una imagen más consolidada respecto a las diferentes dimensiones sociales en las que se pueden analizar ambas actividades.

El reconocimiento del carácter social tanto de la ciencia, como de la tecnología y de la influencia de estas sobre la sociedad, así como sus interacciones e iteraciones recíprocas, ha permitido también nuevos avances teóricos en diferentes campos del conocimiento, como es el caso de la Filosofía de la Tecnología, que arriba a desarrollos espectaculares en la comprensión de la simbiosis que se produce entre la sociedad y las tecnologías, a lo que se añade, desde la década de los setenta, la dimensión cultural de la tecnología para el desarrollo. La cultura, que se enfocaba antes de manera restrictiva, incluye también a las técnicas y la tecnología, así como las formas organizativas de interacción social (Moya, 2002).

Estos elementos de orden teórico sustentan las bases del estudio realizado, que se enmarca en la concepción ampliada de práctica tecnológica que introduce Arnold Pacey, con el objetivo de fundamentar la práctica tecnológica interactiva de Vinicultura Artesanal Urbana (VAU) en Cienfuegos, Cuba, como un elemento de la identidad cultural, para lo cual se analizó durante el periodo 1994-2012, la actividad que desarrollan los asociados a los clubes de vinicultores Guanaroca y Jagua de esa ciudad.

Se constató, que no existía una sistematización teórica de la producción, de la comercialización y de las relaciones sociales que se establecían producto de la actividad de la vinicultura artesanal, ni en Cienfuegos, ni en Cuba. Tampoco se había explorado esa práctica tecnológica en su carácter identitario.

La perspectiva de análisis dialéctico, permitió una comprensión histórica y lógica del objeto de estudio en el contexto socio-cultural de Cienfuegos. Se aplicaron los métodos teóricos de análisis y síntesis, el hipotético deductivo, y métodos propios de la metodología cualitativa, la fenomenología, la etnografía y la teoría fundamentada. Como técnica, se utilizaron principalmente la experiencia personal, la observación participante, además de la entrevista y la encuesta.

La novedad del trabajo radica en que estableció por primera vez, a la práctica tecnológica de VAU como un elemento diferenciador y de la identidad de la ciudad de Cienfuegos, y la utilización metodológica de la propuesta teórica desarrollada por Bansart (1993) sobre la identidad cultural del yo colectivo. 


\section{La dimensión social de la tecnología}

El constructo teórico de Práctica Tecnológica o Triángulo de Pacey (Pacey, 1990), el cual supera la imagen estrecha de tecnología y devela las interdependencias que se producen entre esta y la sociedad. El reconocer las esferas del usuario y del experto como entes a considerar para el éxito de una tecnología, desde la perspectiva de su dimensión humana, supuso un valioso avance de una importancia transcendental para la humanidad.

Referir el aspecto cultural o ideológico de la práctica tecnológica, es reconocer la dimensión cultural amplia de la tecnología. Pacey representa los tres aspectos: técnico, organizacional y cultural de la tecnología en su Triángulo de Práctica Tecnológica (Pacey, 1990: 19). Cuando se habla de tecnología en sentido restringido, los valores culturales y los factores organizativos son considerados como algo externo a ella, reduciéndola por completo a sus aspectos técnicos: al hablar de este modo es más apropiado usar la palabra técnicas.

... era necesario extender aún más la definición de práctica tecnológica, $[\ldots]$ para abarcar el componente orgánico, tanto como al de la estructura. Con ello la tecnología-práctica viene a ser la aplicación del conocimiento científico y organizado a las tareas prácticas por medio de sistemas ordenados que incluyen a las personas, las organizaciones, los organismos vivientes y las máquinas... (Pacey, 1990: 21)

Puesto que la transferencia de tecnología establece una relación de intercambio e interacción recíproca y dinámica con el contexto incidido, termina mediatizando la identidad cultural, que es en definitiva una arista de la identidad de ese contexto.

Los procesos de identidad, así como el lugar y significado del entramado tecnológico, no se producen en abstracto, se materializan y toman cuerpo en un contexto histórico-geográfico, donde pueden entonces distinguirse en un entorno más general, por lo que algunas características se conservarán reforzándose y convirtiéndose en ejes, otras se modificarán y otras cederán su lugar a nuevos elementos de identidad (Moya, 2002: 81)

De ahí la importancia del concepto práctica tecnológica interactiva para significar la dimensión contextual y sociocultural de la tecnología, entendida como la práctica tecnológica que se dinamiza, se desarrolla, se difunde y se arraiga a partir de las interacciones e iteraciones sociales de aquellas personas que la practican y de aquellas que la consumen (usuarios), y que reflejan el aspecto cultural de la tecnología. La red social que conforman estos actores se constituye en un espacio 
importante de diálogo de saberes y experiencias vividas respecto a la práctica tecnológica en cuestión.

En otra arista, desde la década de 1970, la UNESCO comenzó a reconsiderar los métodos de integración de la cultura y el desarrollo, y propuso una interacción dialéctica, que implicó la redefinición de ambos conceptos. Desde esta visión, en que cultura y desarrollo se entrelazan (Miranda, 1999), el fenómeno de la identidad cultural, adquiere especial connotación para el paradigma de la sustentabilidad.

En el plano filosófico la identidad cultural ha sido ampliamente abordada, pero de manera general, el tratamiento en torno al papel del factor tecnológico, ha evidenciado insuficiencias, y es escaso, y han prevalecido hasta hace poco, las imágenes tradicionales, estrechas sobre la tecnología.

La conceptualización sobre la identidad ha transitado una extensa evolución histórica y epistemológica.

Se comprende por identidad cultural, un proceso de caracterización históricamente condicionado, que le confiere sentido a un sujeto social y le aporta criterios valorativos para asumirse como unidad. Esto implica de una u otra forma el reconocimiento o identificación en dos direcciones: autoreconocimiento y reconocimiento de otros (Moya, 2002: 28)

La identidad cultural no se establece como conjunto o conjuntos fijos, inmutables, de características dadas y perennes, se constituye de manera activa y dinámica, no es una mera entidad inerte, abstracta, inconexa, sino que se establece sobre relaciones contextuales vivificantes, que la generan y proyectan. Se reconoce que la identidad cultural es a la vez histórica y prospectiva. La identidad cultural se constituye de procesos, modos y estilos de vida, formas culturales, económicas, lingüísticas, ideológicas, políticas, etc. (Ainsa, 1986: 26).

Una de las fortalezas del pensamiento latinoamericano en estudios sociales de ciencia y tecnología es precisamente la abundante teorización sobre identidad cultural. De entre muchos, es significativa la obra de Andrés Bansart, por la profundidad y acabado de su comprensión sobre el tema:

Para que el yo colectivo pueda definir su identidad cultural necesita fundamentos objetivos y subjetivos. Los primeros se basan en referentes verificables, mientras los segundos se basan en referentes no verificables. Los referentes objetivos son de orden interno (los elementos constitutivos del mismo yo colectivo) y de orden externo (los elementos constitutivos de su ambiente); mientras los elementos subjetivos son únicamente de orden interno (como los 
sentimientos, las creencias y las vivencias del yo colectivo). Las interrelaciones de todos estos elementos son los que permiten al yo colectivo definir su identidad cultural. (Bansart, 1993: 13)

El yo colectivo es un constructo teórico en el cual el yo individual se extrapola a la sociedad para establecer lo que es propio de esa sociedad, agrupa a todos los rangos que son atributos de un grupo de personas, de una sociedad que la hace ser ella y no otra.

Se establece de esta manera, un referente metodológico que permite evaluar una actividad productiva, creativa, tecnológica u otra, como un elemento de identidad en la diferencia y clasificar las características que lo definen. La identidad cultural afirma Bansart, es un proceso concientizador, movilizador, y creativo del ser colectivo en relación a sí mismo y a su ambiente natural y social:

La identidad cultural no está hecha de una vez y para siempre, el "ser colectivo" es el resultado de un proceso de nunca acabar; se está haciendo así mismo a partir de un conocimiento de sí mismo y de su ambiente, y en función a un proyecto de sí en un ambiente que el mismo va transformando. La realización de sí mismo en un ambiente en transformación continua se va objetivando en una Historia, que es, al mismo tiempo, conocimiento del pasado, identidad en el presente y proyecto de desarrollo. Es la conciencia hecha posible por el proceso de identificación socio-cultural la que permite al ser colectivo determinar libremente su futuro material y existencial. (Bansart, 1993: 39-40)

Se asume el criterio de Bansart “... la dinámica de la identidad, consiste en un reconstituirse que, le permite mantener y conservar las constantes de sus ingredientes y elementos originarios, con aquellos incorporados que adquirieron arraigo y permanencia en ella..." (Bansart, 1993: 32).

\section{Antecedentes y organización social de la vinicultura artesanal en Cuba}

Una de las actividades que a través de los siglos ha navegado al lado y con nuestra cultura occidental es el cultivo de la vid y el uso de sus frutos como alimento y como bebida. En 1995 la producción de uvas alcanzaba 60 millones de toneladas, ocupaba el cuarto lugar entre las frutas por su volumen de producción y estaban cultivadas en todos los continentes, en alrededor de 8,2 millones de hectáreas de terreno y en la actualidad abarca unos 7,5 millones de hectáreas (OIV, 2014). 
En Cuba desde los primeros tiempos de la colonia se intentó introducir variedades europeas de vid y desarrollar viñedos, pero estos intentos fueron mayormente fallidos por las enfermedades en la plantación, a causa del clima cálido y húmedo. Ello incitó la producción de vinos a partir de otras frutas. Se reconoce la existencia en la etapa republicana (1902-1958) de varias casas productoras de vinos de frutas, en las que a los mostos se agregaba además azúcar y agua. Sobresale el vino de frutabomba (carica papaya).

Luego de 1959, la nacionalización de las empresas eliminó casi por completo la producción vinícola privada cubana y los toneles de las casas productoras de vino, en el mejor de los casos, fueron redistribuidos a empresas productoras de ron. La actividad vitícola que había estado relegada por siglos, primero por causas económicas, al ser el cultivo de la vid, como muchos otros, desplazado por el de la caña de azúcar y por la no existencia de una cultura propiamente dicha del cultivo, se hizo casi inexistente.

Sin embargo, la tradición de elaborar vino artesanal, traída y sostenida por españoles y sus descendientes se mantuvo viva y acomodada a las condiciones del país. En algunas ciudades de la isla en los años ochenta se constituyeron los primeros Clubes de Vinicultores (Sosa, 2016).

La demolición del Muro de Berlín en 1989 marcó el inicio de una nueva etapa. En condiciones y en disyuntivas casi de sobrevivencia del Régimen Socialista, germinó un ciclo de descentralización económica. Se sitúa esa etapa entre los años 1993-1996. Destaca la creación de una segunda moneda y las Casas de Cambio de Moneda (CADECA). Se creó, el 14 de julio de 1994, La Organización Nacional para la Atención Tributaria (ONAT). Entre las actividades permitidas para ejercer el trabajo por cuenta propia se definió la actividad codificada 441, Elaborador - Vendedor de vinos (ONAT, 2011 y 2014).

La aparición de la figura jurídica de cuentapropista elaborador-vendedor de vinos, la conformación en 1993 de la Coordinadora Nacional de Clubes de Vinicultores de Cuba (CNCVC) y la celebración anual de los Festivales Nacionales de Clubes de Vinicultores consolidó los clubes y contribuyó determinante al florecimiento de la vinicultura artesanal en algunas ciudades de la isla (Sosa, 2016). 


\section{La vinicultura artesanal en la ciudad de Cienfuegos.}

En la ciudad de Cienfuegos, se fundó el Club de Vinicultores Guanaroca el 19 de noviembre de $1989 .{ }^{1}$ El club no tenía, ni tiene personalidad jurídica, era representado por la Casa de Cultura Municipal, la cual además funcionaba como su hospedero. En los primeros años la producción tenía carácter hedonista y su calidad era cuestionable, en la mayoría de los casos. La mayor parte de los vinicultores eran personas con pocos conocimientos enológicos, escaso vocabulario técnico y solo poseían algunos pocos recipientes de $20 \mathrm{~L}$ de cristal. Mayormente no existían etiquetas privadas.

Con el favor de sus conocimientos, la necesidad económica y las nuevas leyes de apertura económica del primer lustro de los años noventa, muchos asociados solicitaron y recibieron la licencia que les permitía la elaboración y comercialización de sus propios vinos artesanales, en su domicilio. La actividad se transformó pronto, para muchos, en una empresa familiar. El transcurso de los años, el empeño y la necesidad fueron modificando la situación al ritmo de la capacidad técnica y la comprensión de los propios vinicultores. El vino fue mejor, y mayor su aceptación entre los coterráneos, por lo que sucesivos ciclos de aumento de la producción y aceptación se produjeron. ${ }^{2}$

Luego de 1996 las reformas se desaceleraron y para el 2003 se inició un ciclo de centralización económica (L. González, 2013). En 1999 eran 35 los cuentapropistas vinicultores, en el año 2000 eran 24, y para el 2010 eran solo 14. La disminución paulatina del número puede entenderse si se considera que el Gobierno congeló la entrega de nuevas patentes luego del año 2002. En el año 2010, se incluyó a la vinicultura en el Movimiento de La Granja Urbana en el municipio de Cienfuegos. ${ }^{3}$ Recibe por ello ventajas como un impuesto tributario menor sobre las ventas que el de la ONAT y permite comercializar en puntos de venta estatales.

En un nuevo ciclo de descentralización de la economía, propiciado en gran parte por otra difícil situación económica y financiera en el país, el gobierno aprobó en 2010 una serie de medidas encaminadas a oxigenar el modelo económico.

\footnotetext{
1 El club Guanaroca llegó a tener en plantilla de más de 100 miembros, luego varios factores se conjugaron para que muchos vinicultores asociados se retiraran, se cita: emigración del país, traslado a trabajos mejor remunerados, pero exigentes en tiempo y dedicación, disconformidad con mandatos centralistas y absolutistas en el seno del club, fallecimiento, desmotivación por la congelación de la figura de elaborador-vendedor en el año 2002, entre otras.

${ }^{2}$ En el año 2000, también en Cienfuegos, el 3 de diciembre se fundó el Club de Vinicultores Jagua.

${ }^{3}$ Movimiento de la Granja Urbana. ${ }^{3}$ Este es un Movimiento Nacional que responde a las políticas de Agricultura Sustentable y a la de Independencia Alimentaria.
} 


\section{Rasgos de la Vinicultura Artesanal Urbana que la identifican como elemento de la identidad cultural de Cienfuegos, 1992-2012.}

Se adopta como criterio, para este análisis, que el yo colectivo es el grupo de vinicultores asociados a los clubes. Se consideró como universo a todos los vinicultores asociados a la Coordinadora Nacional de Clubes de Vinicultores de Cuba y la muestra los vinicultores asociados en Cienfuegos, en el año 2012. Las características identificadas se agruparon de la siguiente forma.

Fundamentos objetivos (verificables) del yo colectivo.

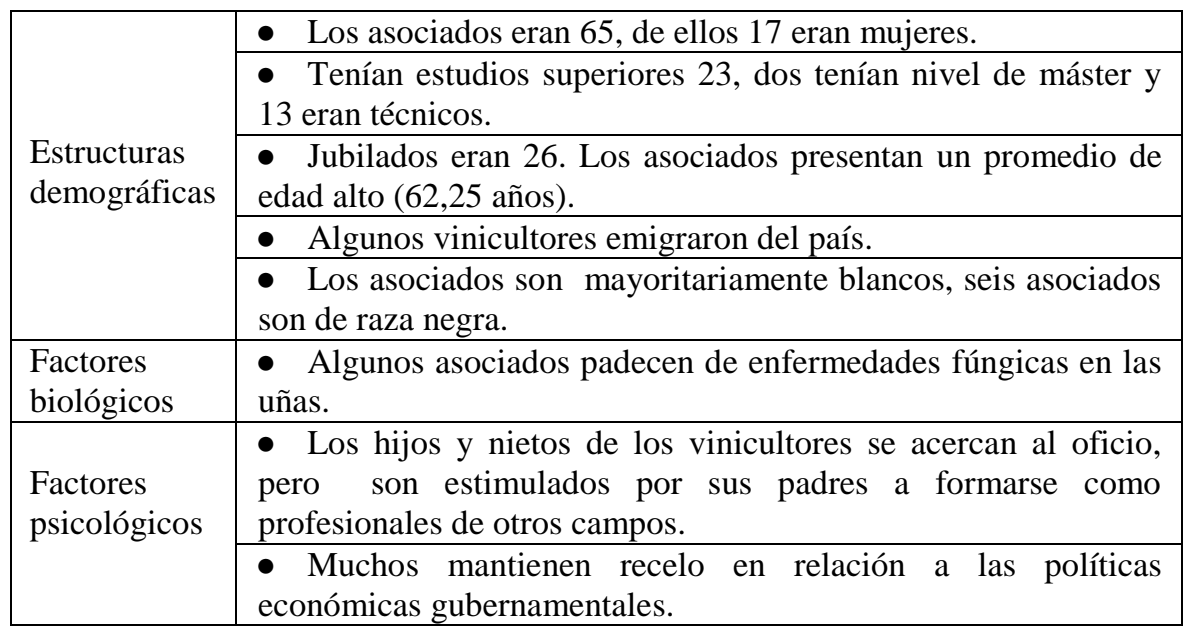

Tabla I. Fundamentos objetivos (verificables) del yo colectivo, características internas. Fuente: Sosa, 2014.

\begin{tabular}{|c|c|}
\hline \multirow{4}{*}{$\begin{array}{l}\text { Organiza- } \\
\text { ción social }\end{array}$} & $\begin{array}{l}\text { - Existe una red social, agrupados en dos clubes. } \\
\text { - La comercialización se produce por elaboradores-vendedores } \\
\text { bajo la figura de cuentapropista (patente-441), y por asociados a } \\
\text { la Granja Urbana desde el año } 2010 .\end{array}$ \\
\hline & $\begin{array}{l}\text { - Se comercializa mayormente en el domicilio del vinicultor- } \\
\text { cuenta propia. }\end{array}$ \\
\hline & $\begin{array}{l}\text { - Las personas inscritas en la ONAT (código 441) en } 2010 \text { eran } \\
14 \text {, ocho eran mujeres. }\end{array}$ \\
\hline & $\begin{array}{l}\text { - En el 2012, } 36 \text { asociados pertenecían a la Granja Urbana, de } \\
\text { ellos seis eran mujeres. }\end{array}$ \\
\hline
\end{tabular}




\begin{tabular}{|c|c|}
\hline & - Existe una red social, agrupados en dos clubes. \\
\hline \multirow{19}{*}{$\begin{array}{l}\text { Modo de } \\
\text { producción }\end{array}$} & $\begin{array}{l}\text { - Los vinos son elaborados con técnicas y tecnologías } \\
\text { artesanales. }\end{array}$ \\
\hline & - El vino artesanal pertenece a la categoría de vino tranquilo. \\
\hline & - La vinicultura se devela como práctica tecnológica interactiva. \\
\hline & $\begin{array}{l}\text { - Los vinos son elaborados no solo a partir del jugo de la uva, } \\
\text { sino que se utilizan además frutas tropicales, flores e incluso } \\
\text { plantas aromáticas y plantas medicinales. }\end{array}$ \\
\hline & $\begin{array}{l}\text { - Se agrega azúcar y agua, alrededor de } 25 \mathrm{~kg} \text { de azúcar por } \\
\text { cada } 100 \text { litros de mosto }\end{array}$ \\
\hline & - El añejamiento es escaso y se hace por reducción. \\
\hline & $\begin{array}{l}\text { - Se utilizan botellas de cristal recicladas, de vino y de ron, que } \\
\text { se compran a recolectores. No tienen acceso a botellas nuevas. }\end{array}$ \\
\hline & $\begin{array}{l}\text { - Se emplean herramientas de uso doméstico como licuadoras, } \\
\text { coladores, embudos. }\end{array}$ \\
\hline & $\begin{array}{l}\text { - Utiliza mayormente tapas y tapones plásticos de material } \\
\text { reciclado y poca fiabilidad. }\end{array}$ \\
\hline & $\begin{array}{l}\text { - Las etiquetas son impresas algunas en papel cromado, las } \\
\text { menos en pegatinas. }\end{array}$ \\
\hline & $\begin{array}{l}\text { - La materia prima fundamental (azúcar), se comercializaba en } \\
\text { tiendas minoristas a un alto precio de alrededor de dos dólares el } \\
\text { kilogramo, ahora a } 50 \text { centavos de dólar. }\end{array}$ \\
\hline & $\begin{array}{l}\text { - Se utilizaban además otros compuestos azucarados } \\
\text { fermentables, solos y también en combinación con el azúcar, tales } \\
\text { como guarapo, raspadura, etc. }\end{array}$ \\
\hline & $\begin{array}{l}\text { - La elaboración y demás procesos, se realiza preferentemente } \\
\text { en botellones de cristal de } 20 \text { litros y tanques plásticos de } 100 \\
\text { litros. }\end{array}$ \\
\hline & $\begin{array}{l}\text { - No existe un mercado de insumos, para clarificantes, } \\
\text { estabilizadores del proceso, tecnologías especializadas y otras } \\
\text { necesidades del proceso productivo. }\end{array}$ \\
\hline & - Como clarificantes, se utiliza bentonita, agar y gelatina. \\
\hline & - Se utilizan pocos estabilizadores, el benzoato es el más común. \\
\hline & $\begin{array}{l}\text { - Los vinos se comercializan mayormente jóvenes, entre los tres } \\
\text { meses y los dos años. }\end{array}$ \\
\hline & $\begin{array}{l}\text { - La dualidad de actividades, muchos asociados comparten y } \\
\text { desempeñan con éxito tanto su profesión como la vinicultura. }\end{array}$ \\
\hline & - El vino se comercializa tanto al tiempo como refrigerado. \\
\hline
\end{tabular}




\begin{tabular}{|l|l|}
\hline \multirow{7}{*}{} & $\begin{array}{l}\bullet \text { No se realizan operaciones comerciales de ningún tipo a través } \\
\text { de Internet. }\end{array}$ \\
\cline { 2 - 3 } & $\begin{array}{l}\bullet \text { La carga tributaria a la ONAT es alta y está basada en los } \\
\text { ingresos brutos. }\end{array}$ \\
\hline $\begin{array}{l}\bullet \text { No estaba, ni está permitida la compra de tecnologías en el } \\
\text { exterior. }\end{array}$ & $\bullet \quad$ Ningún vinicultor asociado había importado tecnologías. \\
\hline & $\bullet$ No se realizan operaciones comerciales por Internet. \\
\hline & $\bullet$ Los asociados nunca utilizan guantes. \\
\hline
\end{tabular}

Tabla II. Fundamentos objetivos, características internas socioculturales. Fuente: Sosa, 2014.

\begin{tabular}{|c|c|}
\hline \multirow{7}{*}{$\begin{array}{l}\text { Sistemas } \\
\text { económicos }\end{array}$} & $\begin{array}{l}\text { - El precio del vino artesanal es relativamente bajo. } \\
\text { Mayormente desde } 0.45 \text { centavos de dólar hasta } 1,25 \text { dólares. } \\
\text { Está en correspondencia con las materias primas utilizadas, el } \\
\text { costo de producción y el nivel adquisitivo su entorno social. }\end{array}$ \\
\hline & - La VAU es cuando más una empresa artesanal familiar. \\
\hline & $\begin{array}{l}\text { - La VAU no tiene especialmente para sí misma un sustento } \\
\text { rural, no tiene tampoco mecanismos que le faciliten los } \\
\text { productos agrícolas desde el campo. }\end{array}$ \\
\hline & $\begin{array}{l}\text { - La Granja Urbana tiene un gravamen tributario sobre las } \\
\text { ventas del } 3 \% \text {. }\end{array}$ \\
\hline & $\begin{array}{l}\text { - Solo } 17 \% \text { de los asociados poseían computadora en su } \\
\text { casa. }\end{array}$ \\
\hline & $\begin{array}{l}\text { - Solo dos asociados poseían Marca Comercial Registrada en } \\
\text { el Registro Nacional de Marcas y Patentes de Cuba. }\end{array}$ \\
\hline & $\begin{array}{l}\text { El vino no se exporta, ni se comercializa en restaurantes o } \\
\text { tiendas especializadas. }\end{array}$ \\
\hline \multirow{5}{*}{$\begin{array}{l}\text { Sistemas } \\
\text { políticos }\end{array}$} & $\begin{array}{l}\text { - El club de vinicultores no tenía, ni tiene figura jurídica } \\
\text { propia. }\end{array}$ \\
\hline & $\begin{array}{l}\text { El gobierno, en el año 2000, estableció la condicionante de } \\
\text { ser primero trabajador suyo, para luego ejercer conjuntamente } \\
\text { como cuentapropia. }\end{array}$ \\
\hline & - Solo poseen auto propio el 3\% de los asociados. \\
\hline & $\begin{array}{l}\text { - Hasta el 2010, la vinicultura artesanal estuvo vinculada al } \\
\text { Ministerio de Cultura, luego al de Agricultura. }\end{array}$ \\
\hline & - Los asociados no tienen representación política alguna o \\
\hline
\end{tabular}




\begin{tabular}{|c|c|}
\hline & influencia sobre el sistema legislativo. \\
\hline \multirow[t]{2}{*}{$\begin{array}{l}\text { Sistema de } \\
\text { valores }\end{array}$} & $\begin{array}{l}\text { - Algunas patentes (marcas) de vino artesanal, por la seriedad } \\
\text { de su trabajo y arraigo popular forman parte de la identidad de } \\
\text { la ciudad. }\end{array}$ \\
\hline & - Se reconoce el valor del trabajo, del talento y de la familia. \\
\hline \multirow{3}{*}{ Normas } & $\begin{array}{l}\text { - Para pertenecer a la Granja Urbana, es condición } \\
\text { indispensable pertenecer a alguno de los dos clubes. }\end{array}$ \\
\hline & $\begin{array}{l}\text { - Los vinicultores se reúnen una vez al mes y cotizan } \\
\text { membrecía. }\end{array}$ \\
\hline & $\begin{array}{l}\text { - Se propicia la participación en eventos culturales de la } \\
\text { localidad. }\end{array}$ \\
\hline \multirow[t]{2}{*}{$\begin{array}{l}\text { Sistema de } \\
\text { cooperación }\end{array}$} & $\begin{array}{l}\text { - La red social (el club y la coordinadora) juega un } \\
\text { importante papel como difusora del conocimiento científico, } \\
\text { técnico y empírico. }\end{array}$ \\
\hline & - Se comparten proveedores, contactos y relaciones sociales. \\
\hline \multirow{9}{*}{$\begin{array}{l}\text { Sistema de } \\
\text { comunicación }\end{array}$} & $\begin{array}{l}\text { - Los asociados a los clubes tienen incorporado a su léxico } \\
\text { las palabras propias de la práctica tecnológica, a diferencia de } \\
\text { las personas ajenas a los clubes. }\end{array}$ \\
\hline & $\begin{array}{l}\text { - Solo el } 20 \% \text { de los asociados ha utilizado alguna vez } \\
\text { internet (aunque sea una). }\end{array}$ \\
\hline & - Solo el $5 \%$ revisa Internet regularmente o dispone de ella. \\
\hline & - Solo $12,3 \%$ de los asociados poseían teléfono celular. \\
\hline & $\begin{array}{l}\text { - La vinicultura artesanal de Cienfuegos no tiene sitios web, } \\
\text { ni publicaciones propias. }\end{array}$ \\
\hline & $\begin{array}{l}\text { - El vino artesanal no se promociona directamente en medios } \\
\text { masivos. }\end{array}$ \\
\hline & $\begin{array}{l}\text { - La vinicultura artesanal publica informaciones sobre } \\
\text { eventos de vinicultura en los medios de comunicación locales y } \\
\text { sitios digitales. }\end{array}$ \\
\hline & $\begin{array}{l}\text { - La etiqueta y el cartel en domicilio son las formas } \\
\text { principales de propaganda. }\end{array}$ \\
\hline & $\begin{array}{l}\text { - Los vinicultores participan en las emisiones de radio y de } \\
\text { TV. }\end{array}$ \\
\hline \multirow[t]{4}{*}{ Hábitos } & $\begin{array}{l}\text { - Consumo moderado de vino, la mayoría consume además } \\
\text { cerveza y ron. }\end{array}$ \\
\hline & - Buena Higiene personal y doméstica. \\
\hline & - Buena higiene personal y doméstica. \\
\hline & - Debatir sobre vinicultura. No debatir ni de política, ni de \\
\hline
\end{tabular}




\begin{tabular}{|c|c|}
\hline & religión. \\
\hline Costumbres & $\begin{array}{l}\text { - La reunión mensual es el marco en el que se intercambian } \\
\text { experiencias y se degustan los vinos. }\end{array}$ \\
\hline \multirow{3}{*}{ Conductas } & $\begin{array}{l}\text { - Los asociados emplean en su léxico palabras propias de la } \\
\text { práctica tecnológica. }\end{array}$ \\
\hline & $\begin{array}{l}\text { El consumo de alcohol es moderado, aproximadamente } 500 \\
\text { ml de vino diario. Algunos apenas consumen alcohol. }\end{array}$ \\
\hline & $\begin{array}{l}\text { - En general los asociados respetan las leyes y patrones de } \\
\text { conducta de la sociedad. }\end{array}$ \\
\hline \multirow[t]{7}{*}{$\begin{array}{l}\text { Estructuras } \\
\text { familiares }\end{array}$} & $\begin{array}{l}\text { - La actividad vinicultor-cuentapropista se establece como un } \\
\text { negocio familiar. mayoría de los vinicultores tiene una familia } \\
\text { estable y funcional. }\end{array}$ \\
\hline & $\begin{array}{l}\text { - La etiqueta privada, estas evolucionaron desde blancas y } \\
\text { negras, con símbolos primarios, y muy sencillas, a coloreadas, } \\
\text { de elaborados y equilibrados diseños. }\end{array}$ \\
\hline & $\begin{array}{l}\text { - La etiqueta en los primeros años incluyen solo elementos de } \\
\text { identidad y el volumen, luego incorporan además elementos } \\
\text { que versan sobre el producto. }\end{array}$ \\
\hline & $\begin{array}{l}\text { - La ficha de cata evolucionó desde una descriptiva criolla en } \\
\text { los años noventa, a una internacional basada en la de la escuela } \\
\text { de Burdeos, luego del año } 2002 \text {. }\end{array}$ \\
\hline & $\begin{array}{l}\text { Desde la venta a granel, a ventas como vino embotellado. } \\
\text { Subsisten las dos formas. }\end{array}$ \\
\hline & $\begin{array}{l}\text { - La valoración de la sociedad y la autovaloración como } \\
\text { vinicultor es cada vez mayor. }\end{array}$ \\
\hline & $\begin{array}{lllllll}\text { - Se incrementaron los medios de producción y lo } \\
\text { conocimientos. }\end{array}$ \\
\hline
\end{tabular}

Tabla III. Fundamentos objetivos del yo colectivo, características socioculturales. Fuente: Sosa, 2014.

\begin{tabular}{|l|l|}
\hline \multicolumn{2}{|c|}{ ambiente natural (Orbe y Barcia, 2007) } \\
\hline Entorno físico & $\begin{array}{l}\text { No existen viñedos reportados en la provincia de } \\
\text { Cienfuegos. }\end{array}$ \\
\cline { 2 - 2 } & $\begin{array}{l}\text { - Las temperaturas medias de alrededor de } 28^{\circ}-31^{\circ} \mathrm{C} \\
\text { propician enfermedades (antracnosis y mildiú) causadas por } \\
\text { hongos. }\end{array}$ \\
\cline { 2 - 2 } & $\bullet$ Las altas temperaturas, afectan las etapas del vino y sobre \\
\hline
\end{tabular}




\begin{tabular}{|c|c|}
\hline & todo su conservación. \\
\hline \multirow[t]{2}{*}{ Tierra } & $\begin{array}{l}\text { - Las tierras de la región son muy fértiles y producen gran } \\
\text { variedad de frutas. }\end{array}$ \\
\hline & - En la ciudad el terreno está muy antropizado. \\
\hline \multirow{2}{*}{ Agua } & $\begin{array}{l}\text { - Buen régimen de precipitaciones, que favorece los cultivos } \\
\text { (media de } 1304 \mathrm{~mm} \text { anuales y humedad relativa del } 78 \% \text { ). }\end{array}$ \\
\hline & $\begin{array}{l}\text { - Los temporales lluviosos propician enfermedades causadas } \\
\text { por hongos. }\end{array}$ \\
\hline \multirow[t]{2}{*}{$\begin{array}{l}\text { Medio } \\
\text { biológico } \\
\text { [seres vivos] }\end{array}$} & $\begin{array}{l}\text { - La enfermedad Mildiú, causada por el hongo Plasmopara } \\
\text { vitícola Berl y de Tony y la Antracnosis, enfermedad causada } \\
\text { por hongos pertenecientes a los géneros Colletotrichum y } \\
\text { Gloeosporium afectan a las vides cienfuegueras. }\end{array}$ \\
\hline & - Solo 10 asociados poseían vid (Vitis ssp) propia. \\
\hline \multirow{3}{*}{$\begin{array}{l}\text { Identidad } \\
\text { cultural del } \\
\text { otro }\end{array}$} & $\begin{array}{l}\text { - Los conciudadanos aceptan bien el vino artesanal, pero } \\
\text { más populares son el ron y la cerveza. }\end{array}$ \\
\hline & $\begin{array}{l}\text { La cultura sobre vinos es pobre, y no hay cultura del cultivo } \\
\text { de la vid. }\end{array}$ \\
\hline & - No hay una cultura del debate público. \\
\hline $\begin{array}{l}\text { Características } \\
\text { demográficas }\end{array}$ & $\begin{array}{l}\text { - La población que consume vino abarca jóvenes y adultos, } \\
\text { de cualquier nivel escolar, profesión, raza, género y poder } \\
\text { adquisitivo. }\end{array}$ \\
\hline $\begin{array}{l}\text { Características } \\
\text { biológicas }\end{array}$ & $\begin{array}{l}\text { - Los clientes con un consumo regular y moderado del vino } \\
\text { artesanal refieren tener una buena y rápida digestión. }\end{array}$ \\
\hline $\begin{array}{l}\text { Características } \\
\text { psicológicas }\end{array}$ & $\begin{array}{l}\text { - El vino artesanal es bien aceptado entre los conciudadanos } \\
\text { de Cienfuegos. }\end{array}$ \\
\hline \multirow{5}{*}{$\begin{array}{l}\text { Características } \\
\text { socioculturales }\end{array}$} & $\begin{array}{l}\text { - El precio del vino artesanal es relativamente bajo, pero está } \\
\text { en correspondencia con el costo de producción y con el } \\
\text { entorno social. }\end{array}$ \\
\hline & $\begin{array}{l}\text { - La enología no es está incluida en ningún currículo } \\
\text { universitario o técnico del país. }\end{array}$ \\
\hline & $\begin{array}{l}\text { - El contexto rural produce muy poco vino y salvo } \\
\text { excepciones no comercializa vino. }\end{array}$ \\
\hline & $\begin{array}{l}\text { - No está permitido (por ley) el empleo de fondos financieros } \\
\text { para la suscripción en el exterior a revistas temáticas o la } \\
\text { importación de tecnologías. }\end{array}$ \\
\hline & $\begin{array}{l}\text { - La práctica tecnológica de la vinicultura artesanal, depende } \\
\text { de muchos factores jurídicos y legislativos, algunos no son }\end{array}$ \\
\hline
\end{tabular}




\begin{tabular}{|l|l|}
\hline \multirow{4}{*}{$\begin{array}{l}\text { Historia } \\
\text { propia }\end{array}$} & $\begin{array}{l}\text { favorables. } \\
\text { de transporte) está cercenado. }\end{array}$ \\
\hline & $\begin{array}{l}\text { patrimoniales se interrumpió con las nacionalizaciones a la } \\
\text { propiedad privada en la década de 1960. }\end{array}$ \\
\cline { 2 - 3 } & $\begin{array}{l}\text { — Existen antecedentes de personas que compartieron sus } \\
\text { conocimientos en la elaboración de vinos desde el exterior o } \\
\text { desde antiguas fábricas de vino y/o ron. }\end{array}$ \\
\cline { 2 - 3 } & $\begin{array}{l}\text { — Las características actuales de la Vinicultura Artesanal } \\
\text { Urbana (VAU) están condicionadas por leyes y antecedentes } \\
\text { históricos, sociales y naturales del país. }\end{array}$ \\
\hline
\end{tabular}

Tabla IV. Características externas dentro de los fundamentos objetivos. Fuente: Sosa, 2014.

\begin{tabular}{|c|c|}
\hline \multicolumn{2}{|l|}{ Sentimientos } \\
\hline Amor/odio & $\begin{array}{l}\text { - La vinicultura es para el vinicultor fuente de regocijo } \\
\text { espiritual. }\end{array}$ \\
\hline \multirow[t]{2}{*}{ Atracción/rechazo } & $\begin{array}{l}\text { - Solo se permitió el ingreso a la Granja Urbana a los } \\
\text { vinicultores asociados. }\end{array}$ \\
\hline & $\begin{array}{l}\text { Entre los asociados se palpa respeto, en ocasiones } \\
\text { identificación y competencia. }\end{array}$ \\
\hline \multirow{3}{*}{ Pertenencia } & $\begin{array}{l}\text { - Se sienten en el disfrute de un don, o de un arte a la vez } \\
\text { ciencia. }\end{array}$ \\
\hline & $\begin{array}{l}\text { - Se identifican con su actividad, su entorno y su grupo } \\
\text { social. }\end{array}$ \\
\hline & $\begin{array}{l}\text { - Son dueños de sus medios artesanales de producción y } \\
\text { del resultado de su trabajo. }\end{array}$ \\
\hline \multirow[t]{2}{*}{ Unidad } & $\begin{array}{l}\text { - Se saben participes de las mismas necesidades e } \\
\text { intereses, y de los mismos derechos y deberes como } \\
\text { vinicultores asociados. }\end{array}$ \\
\hline & $\begin{array}{l}\text { - Participan en eventos nacionales como un colectivo que } \\
\text { representa a Cienfuegos. }\end{array}$ \\
\hline \multirow[t]{2}{*}{ Solidaridad } & $\begin{array}{l}\text { - Se interesan por las necesidades y la salud de los } \\
\text { compañeros enfermos o en dificultad. }\end{array}$ \\
\hline & - Comparten relaciones sociales de forma selectiva. \\
\hline Autonomía & $\begin{array}{l}\text { - Los vinicultores comercializadores gozan de una } \\
\text { relativa autonomía para encarar proyectos y realizar }\end{array}$ \\
\hline
\end{tabular}




\begin{tabular}{|c|c|}
\hline & actividades. \\
\hline & $\begin{array}{l}\text { - Encuentran en la VAU una forma de realización } \\
\text { personal y satisfacción espiritual. }\end{array}$ \\
\hline Coherencia & $\begin{array}{l}\text { - Comprenden la necesidad de llevar una familia estable y } \\
\text { una actividad tecnológica responsable, para disfrutar de un } \\
\text { negocio próspero. }\end{array}$ \\
\hline Mentalidades & \\
\hline Modelos & $\begin{array}{l}\text { - Tienen confianza en la vinicultura y en su } \\
\text { autocapacidad para salir adelante. }\end{array}$ \\
\hline & $\begin{array}{l}\text { - A menudo se involucran en proyectos propios, y se } \\
\text { esfuerzan por llevarlos adelante. }\end{array}$ \\
\hline Contra-modelos & $\begin{array}{l}\text { - Saben que existen otros modos en el mundo de practicar } \\
\text { la vinicultura. }\end{array}$ \\
\hline & $\begin{array}{l}\text { - La práctica tecnológica de la vinicultura artesanal } \\
\text { depende también de muchos factores jurídicos y } \\
\text { legislativos, externos a la misma. }\end{array}$ \\
\hline Creencias & \\
\hline Mitos & $\begin{array}{l}\text { - Nombran a sus clubes con nombres de leyendas } \\
\text { indocubanas locales de Cienfuegos. }\end{array}$ \\
\hline & - El vino no solo se produce a partir del zumo de la uva. \\
\hline Religión & $\begin{array}{l}\text { - No se habla de religión en el seno del club, ni en los } \\
\text { eventos nacionales. }\end{array}$ \\
\hline & $\begin{array}{l}\text { - Concurren vinicultores de disimiles creencias y ateos, } \\
\text { predominan los últimos. }\end{array}$ \\
\hline Motivaciones & \\
\hline Necesidades & $\begin{array}{l}\text { - El vinicultor-cuentapropista encuentra en la vinicultura } \\
\text { un proyecto de vida y de interacción con la sociedad. }\end{array}$ \\
\hline & $\begin{array}{l}\text { - Se saben participes de las mismas necesidades e } \\
\text { intereses. }\end{array}$ \\
\hline & - Trabajan por salir adelante. \\
\hline Intereses & $\begin{array}{l}\text { - Necesitan de la interacción social con sus semejantes } \\
\text { vinicultores, por razones sociales, de conocimiento y de } \\
\text { compartir experiencias. }\end{array}$ \\
\hline Reconocimiento & $\begin{array}{l}\text { - Los vinos artesanales son aceptados y reconocidos por } \\
\text { sus conciudadanos. }\end{array}$ \\
\hline $\begin{array}{l}\text { por el sujeto } \\
\text { colectivo }\end{array}$ & $\begin{array}{l}\text { - Participa como VAU en eventos culturales, ferias, } \\
\text { exposiciones y programas radio-televisivos convocados } \\
\text { por el gobierno y las instituciones de la ciudad. }\end{array}$ \\
\hline
\end{tabular}




\begin{tabular}{|c|c|}
\hline \multirow[b]{2}{*}{ Aspiraciones } & $\begin{array}{l}\text { - Aspiran a mejorar su vino, y con ello al reconocimiento } \\
\text { social y la satisfacción espiritual. }\end{array}$ \\
\hline & $\begin{array}{l}\text { Aspiran mejorar su bienestar y el de la familia a través } \\
\text { de la vinicultura. }\end{array}$ \\
\hline Deseos & $\begin{array}{l}\text { - Desean realizar satisfactoriamente sus proyectos de vida } \\
\text { y para ello cuentan con la vinicultura. }\end{array}$ \\
\hline \multirow{2}{*}{$\begin{array}{l}\text { Experiencias de } \\
\text { vida }\end{array}$} & $\begin{array}{l}\text { - Los más jóvenes o inexpertos observan como lo han } \\
\text { hecho aquellos vinicultores que han progresado. }\end{array}$ \\
\hline & $\begin{array}{l}\text { - La calidad alcanzada se debe a sucesivos ciclos de } \\
\text { experiencias y aprendizajes. }\end{array}$ \\
\hline \multicolumn{2}{|r|}{$T_{1}$} \\
\hline \multirow[t]{2}{*}{ Necesidades } & $\begin{array}{l}\text { - Tienen las mismas necesidades en cuanto a insumos, } \\
\text { posibilidades de venta, impuesto y tecnologías. }\end{array}$ \\
\hline & - Necesitan compartir y socializar experiencias. \\
\hline \multicolumn{2}{|l|}{ Sensaciones } \\
\hline \multirow{2}{*}{$\begin{array}{l}\text { Emociones } \\
\text { colectivas }\end{array}$} & $\begin{array}{l}\text { - Han disfrutado por igual los triunfos de la provincia en } \\
\text { eventos nacionales. }\end{array}$ \\
\hline & $\begin{array}{l}\text { - Realiza celebraciones del colectivo, personales y } \\
\text { sociales. }\end{array}$ \\
\hline \multirow{4}{*}{$\begin{array}{l}\text { Choques } \\
\text { emotivos y } \\
\text { traumatismos } \\
\text { culturales }\end{array}$} & $\begin{array}{l}\text { - Siente como propias los descalabros de la vinicultura } \\
\text { cienfueguera en eventos nacionales. }\end{array}$ \\
\hline & $\begin{array}{l}\text { - La congelación de la patente } 441 \text { en } 2002 \text {, desanimó a } \\
\text { muchos vinicultores. }\end{array}$ \\
\hline & $\begin{array}{l}\text { Ven limitadas sus capacidades productivas y de } \\
\text { bienestar por leyes incomprensibles. }\end{array}$ \\
\hline & $\begin{array}{l}\text { - Luego de 2002, la Casa de Cultura fue retirando } \\
\text { paulatinamente su apoyo a los clubes de vinicultores. }\end{array}$ \\
\hline
\end{tabular}

Tabla V. Fundamentos subjetivos (no verificables) del yo colectivo. Fuente: Sosa, 2014.

\section{Conclusiones}

- El estudio fundamentó desde el enfoque CTS y sus herramientas teóricas y metodológicas, que la práctica tecnológica interactiva VAU incide, matiza y contribuye a la identidad cultural de la ciudad de Cienfuegos en el periodo 19942012 y quedó fundamentado como elemento de identidad.

- Más de cuatro quintas partes son elementos socioculturales, lo que confirma la alta simbiosis entre la sociedad y las tecnologías.

- La actividad vinícola artesanal en Cienfuegos, se desarrolla a través de 
una red social de productores urbanos que producen y reproducen su actividad sobre la base de conocimientos adquiridos generacionalmente y/o en el intercambio de experiencias, que la propia organización de la actividad, en clubes, les proporciona.

- Las actividades se realizan con tecnologías simples, basadas en conocimientos tácitos y saberes populares tradicionales, que se amalgaman con el conocimiento científico.

- La vinicultura artesanal en Cienfuegos es un fenómeno urbano, necesita de un soporte rural, pero no tiene vínculos efectivos con el campo. La tecnología es completamente artesanal y no supera los límites de una empresa familiar.

- El esquema de análisis empleado, sustentado en Bansart (1993), se convierte en referente metodológico que permite evaluar una actividad productiva, creativa, tecnológica u otra, como un elemento de identidad en la diferencia y clasificar las características que la definen.

- El modo de producción, el sistema político y sistema económico limitan el desarrollo de la práctica productiva (No créditos, altos impuestos sobre ingresos brutos, no importación de tecnologías, no acceso a Internet y ni revistas temáticas, no acceso a insumos, no acceso a privado a medios de transporte, y no posibilidades de exportación y comercialización, entre otras).

\section{Referencias}

AINSA, Fernando, Identidad Cultural de Iberoamérica en su narrativa, Madrid, Gredos, 1986.

BANSART, Andrés, Cultura-Ambiente-Desarrollo. El caso del Caribe Insular, Caracas, Instituto de altos estudios de América Latina, 1993.

GONZÁLEZ, Linier, "Mi libro sobre las reformas en Cuba. Entrevista a Carmelo Mesa" [Versión electrónica]. Espacio Laical, VIII(3), 2013, 31-38 (en línea). http://www.espaciolaical.org/contens/31/3138.pdf, acceso 29 de mayo de 2014.

GONZÁLEZ, Marta I.; LÓPEZ, José A. y LUJÁN, José L., Ciencia, tecnología y sociedad: una introducción al estudio social de la ciencia y la tecnología ( $1^{\mathrm{a}}$ ed.). Madrid, Tecnos, 1996.

MIRANDA, Clara E., "Enfoques acerca de la relación medio ambiente desarrollo. Referencia histórica", Tecnología y Sociedad, 215-231, La Habana, Editorial Félix Varela, 1999. 
MOYA, Nereida E., Impacto de la tecnología en la identidad cultural. Estudio de caso de la región de Cienfuegos, (1850-1898) [ Tesis Doctoral no publicada], La Habana, Universidad de La Habana, 2002.

OFICINA NACIONAL DE LA ORGANIZACIÓN TRIBUTARIA, [ONAT], Actividades por cuenta propia, La Habana, ONAT, 2011.

OFICINA NACIONAL DE LA ORGANIZACIÓN TRIBUTARIA, [ONAT], Sobre el régimen tributario para el trabajo por cuenta propia, La Habana, ONAT, 2014.

ORGANIZACIÓN INTERNACIONAL DE LA VIÑA Y EL VINO, [OIV], Balance de la OIV sobre la Producción Mundial Vitivinícola. OIV, Ginebra (en línea). Revisado en: http://www.oiv.int/oiv/info/esBilan_OIV_Mainz_2015?lang=es último acceso 1 de septiembre de 2015. 2015.

PACEY, Arnold, La cultura de la tecnología, México D. F, Fondo de Cultura Económica, [1983] 1990.

SOSA, Juan A., MIRANDA, Clara E. y MOYA, Nereida E., Dimensión social de la tecnología. La práctica tecnológica vinicultura artesanal como elemento de la identidad cultural [Versión Kindle], accedido 26 de marzo de 2016, https://www.amazon.es/kindle/dp/B01DFOFTXA/ref=rdr_kindle_ext_eos_detail, 2016 . 